\title{
GRUPO MULTIPROFISSIONAL DE ATENDIMENTO AO DIABETICO: UMA PERSPECTIVA DE ATENÇÃO INTERDISCIPLINAR À SAÚDE ${ }^{1}$ MULTIDISCIPLINARY GROUP FOR DIABETIC NOURISHMENT: A PERSPECTIVE FOR MULTIDISCIPLINARY ATTENTION IN HEALTH CARE LA ATENCIÓN AL DIABÉTICO POR UN GRUPO MULTIPROFESIONAL: SEGÚN LA PERSPECTIVA DE LA ATENCIÓN INTERDISCIPLINAR PARA LA SALUD
}

\author{
Celina Maria Araujo Tavares², Eliane Matos', Leônor Gonçalves ${ }^{4}$
}

${ }^{1}$ Trabalho desenvolvido durante a disciplina História da Enfermagem e da Saúde, oferecida pelo curso de Pós-Graduação em Enfermagem da Universidade Federal de Santa Catarina (UFSC) e orientada pelas doutoras: Maria Itayra Coelho de Souza Padilha e Mirian Süsskind Borenstein.

${ }^{2}$ Enfermeira. Professora aposentada da Universidade Federal de Mato Grosso. Mestre em Enfermagem Obstétrica e Neonatal pela Universidade de São Paulo (USP-SP). Doutoranda do Programa de Pós-Graduação em Enfermagem da UFSC.

${ }^{3}$ Enfermeira. Chefe da Divisão de Enfermagem em Emergência e Ambulatório do Hospital Universitário da UFSC. Mestre em Enfermagem pela UFSC. Doutoranda do Programa de Pós-Graduação em Enfermagem da UFSC.

${ }^{4}$ Enfermeira do Hospital das Clínicas da Universidade Federal de Minas Gerais (UFMG). Mestre em Enfermagem pela UFMG. Doutoranda do Programa de Pós-Graduação em Enfermagem da UFSC.

PALAVRAS-CHAVE: Diabetes mellitus. Assistência ambulatorial. Equipe de assistência ao paciente.

KEYWORDS: Diabetes mellitus. Ambulatory care. Patient care team.

PALABRAS CLAVE: Diabetes mellitus. Atención ambulatorial. Grupo de atención al paciente.

RESUMO: Este trabalho é um estudo de caso do Grupo Multiprofissional de Atendimento ao Diabético que funciona, desde a década de 80, no Hospital Universitário da Universidade Federal de Santa Catarina. Teve por objetivo resgatar, através da história documental, a trajetória do Grupo, pontuando a importância desse trabalho para compreender a multi/interdisciplinaridade e as implicações na organização do processo assistencial ao cliente. Durante a pesquisa foram necessárias a identificação e análise de documentos e, para complementar os dados, a realização de entrevistas. Os dados obtidos demonstram que o Grupo, por sua organização e atuação transita entre a concepção de pluridisciplinaridade e interdisciplinaridade. Suas ações têm concentrado formas de integração entre os saberes, articulando a prática e a construção do conhecimento, compreendendo que a sua concretização exige um pensamento central entre as diversas disciplinas em torno de um projeto comum - a assistência ao cliente com Diabetes Mellitus.

\begin{abstract}
This is a case study of the Multiprofessional Group for Diabetic Care, which has been working since the 1980s in the University Hospital of the Federal University of Santa Catarina. Its objective was to rescue, by means of the registered documentation, the trajectory of the group, pointing out the importance of its efforts in understanding the multidisciplinary reality and their implications for the organization of the health care process for the client. During the research it became necessary to identify and analyze said documents, as well as perform interviews, to complement the data. The data obtained demonstrate that through its organization and existence the Group bridges the gap between the concept of pluridisciplinary and multidisciplinary realities. Its actions have concentrated forms of integration among existing knowledge, articulated the practice and construction of knowledge, understanding that its concretization demands some central thinking among the various disciplines, based on the common project - the health care offered to the client who carries Mellitus Diabetes.
\end{abstract}

RESUMEN: El presente trabajo de naturaleza cualitativa, es un estudio de caso con el Grupo Multiprofesional del Atendimiento al Diabético que funciona, a partir de la década del 80, en el Hospital Universitario de la Universidad Federal de Santa Catarina. Tuvo por objetivo rescatar a través de la historia documental, la trayectoria del grupo, destacando la relevancia e importancia de este trabajo para comprender la multidisciplinaridad e interdisciplinaridad y sus implicaciones en la organización del proceso asistencial al cliente. Para la recolección de los datos en la investigación fue necesario la identificación y el análisis de los documentos, así como, la realización de entrevistas. Los datos obtenidos demostraron que el Grupo, por su organización y su actuación transita dentro de la concepción de la pluridisciplinaridad y de la interdisciplinaridad. Sus acciones han concentrado las diferentes formas de integración entre los saberes, articulando la práctica y la construcción del conocimiento, comprendiendo que su concretización exige de un idea central entre las diferentes disciplinas en torno de un proyecto en común; siendo ésta la asistencia al cliente portador de diabetes mellitus.

Endereço:

Celina Maria Araújo Tavares

R. João Pio Duarte Silva, 1070 Apto 301- E

88037-001 - Córrego Grande, Florianópolis, SC

E-mail: tavares@nfr.ufsc.br
Artigo original: Pesquisa

Recebido em: 15 de novembro de 2004

Aprovação final: 10 de maio de 2005 


\section{INTRODUÇÃO}

Nas últimas décadas, a perspectiva interdisciplinar tem sido apontada como modelo importante para o trabalho em saúde, tanto no que diz respeito aos aspectos de satisfação e motivação do trabalhador, como para uma assistência de maior qualidade aos usuários do sistema de saúde ${ }^{1}$.

Observamos, durante nossa vivência profissional, que nas experiências caracterizadas por ações integradas em saúde, são utilizadas terminologias distintas (multiprofissional, multidisciplinar, interdisciplinar, grupos de apoio e outras) para ações similares, indicando que não existe um consenso na prática sobre estes conceitos. Diversos autores, entretanto, reforçam a importância de que a perspectiva de ações integradas, independente da denominação que recebam multi, inter ou transdisciplinares, têm-se constituído em indicativos para a organização da assistência em saúde ${ }^{2-4}$.

Embora a literatura coloque a existência de diferenças entre tais termos, percebe-se a carência de análise quanto às relações que se estabelecem historicamente nessas práticas. É necessário que seja visto o grau de integração existente entre os profissionais e as ações desenvolvidas, de forma a permitir a análise para além dos termos sob as quais se designam.

A idéia de desenvolver um trabalho na disciplina História da Enfermagem e Saúde, ministrada no Curso de Doutorado em Enfermagem da UFSC, despertou o nosso interesse em analisar iniciativas interdisciplinares. Neste sentido, buscamos uma experiência já implantada e optamos pelo Grupo Multiprofissional de Atendimento ao Diabético (GRUMAD), que funciona no Hospital Universitário da Universidade Federal de Santa Catarina (HU/ UFSC) desde a década de 80 . O objetivo foi resgatar, através da história documental, a trajetória do GRUMAD, pontuando a importância desse trabalho para compreender a multi/interdisciplinaridade e as implicações na organização do processo assistencial ao cliente com diabetes.

Para compreender a temática fez-se necessário levantar, preliminarmente, essas terminologias na literatura e, como todas elas remetiam à palavra disciplina, iniciamos por sua conceituação. Disciplina é uma categoria organizadora do conhecimento científico, que institui a divisão e a especialização do trabalho, conota rigor na atuação e continuidade ou perseverança no enfrentamento de problemas. Foi empregada para referir-se a um tipo de iniciação a uma doutrina, a um método de ensino, posteriormente veio a conotar o ensino-aprendizado em geral. Nas primeiras universidades, passou a designar uma matéria ensinada, um ramo do conhecimento, que depois viria a se chamar de "ciência", tornando-se equivalente à princípios, regras e métodos de um ramo do saber científico ${ }^{5-6}$.

Com o desenvolvimento da ciência, os campos do conhecimento foram se estreitando e aprofundando, especializando-se. Como conseqüência, a especialização foi sendo mais valorizada e competitiva, influenciando a criação de campos disciplinares institucionais com múltiplas divisões internas, tornando-se "ilhas" epistemológicas, dogmáticas e acríticas $^{6-7}$. Atualmente, existem questionamentos quanto ao mérito desses saberes fragmentados ${ }^{5}$.

A necessidade de quebrar esta visão fragmentada fez surgir várias formas de sistematização da ciência e de organização dos campos de prática profissional. Almeida Filho ${ }^{6}$ apresenta a classificação de Jantsch, adaptada por Vasconcelos e Bibeau, que adotamos aqui:

Multidisciplinaridade - agregação de duas ou mais áreas do conhecimento para examinar um mesmo tema sob pontos de vista distintos, sem que os profissionais implicados estabeleçam entre si efetivas relações no campo técnico ou científico. Funciona com a justaposição de disciplinas de um único nível, sem cooperação sistemática entre os diversos campos. Quando existente coordenação é de ordem administrativa e externa ao campo técnico-científico.

Pluridisciplinaridade - forma onde a justaposição permanece, em função de uma mesma área temática, com um mesmo nível de hierarquia. Já se processam as relações entre as várias disciplinas, com algum grau de cooperação, numa perspectiva de complementaridade e com objetivos comuns, mas sem ocorrer coordenação de ações nem qualquer pretensão de criar uma axiomática comum, entendendo a palavra "axiomática" como uma premissa imediatamente evidente que se admite como universalmente verdadeira sem exigência de demonstração [...] dela se podem deduzir as proposições de uma teoria ou de um sistema lógico ou matemático ${ }^{8}$.

Interdisciplinaridade: implica numa axiomática comum a um grupo de disciplinas conexas. As relações são em um nível hierárquico superior ocupado por uma delas, geralmente por referência à sua temática comum, que atua como integradora e mediadora da circulação dos discursos disciplinares e como coordenadora do campo disciplinar. Há reciprocidade, enriquecimento mútuo e tendência à horizontalização das 
relações de poder entre os campos.

Transdisciplinaridade: integração das disciplinas de um campo particular sobre a base de uma axiomática geral compartilhada. É baseada em um sistema com vários níveis e com objetivos diversificados. Há tendência à horizontalização das relações de poder sendo assegurada a coordenação por referência a uma finalidade comum. Implica na criação de um campo novo que desenvolverá uma autonomia teórica e metodológica perante as disciplinas que o compõem.

\section{METODOLOGIA}

Trata-se de um estudo de caso, cuja abordagem privilegia a pesquisa histórica. A pesquisa do tipo ex post tem como objetivo reconstituir fenômenos ocorridos no passado9. "[...] a finalidade da investigação histórica deve ser, explicar o presente e prever os acontecimentos futuros" 10:145. "Os maiores desafios desse tipo de pesquisa estão na existência e no acesso aos dados do passado, bem como nos cuidados metodológicos para reconstruí-los a partir de fontes documentais e vivas, como nas entrevistas com atores que viveram aquele momento"9:203. No desenvolvimento desse tipo de trabalho é necessário seguir três passos para conduzir a investigação: levantamento de dados; avaliação crítica dos dados e apresentação dos fatos; interpretação e conclusões ${ }^{10}$.

$\mathrm{Na}$ perspectiva de compreender a trajetória do GRUMAD buscamos, inicialmente, conhecer o que já havia de documentação sobre o Grupo. No início fomos surpreendidas pelo volume de material documental existente e sem sistematização, que possibilitaria a reconstituição da sua trajetória histórica. Após a análise inicial, optamos em trabalhar com os ofícios, registros das reuniões em Livros de Atas, relatórios de atividades entre outros.

Para a pesquisa foram necessárias a identificação e sistematização dos documentos, com síntese dos conteúdos, organizando-os cronologicamente. O material identificado relatava a: criação, organização e funcionamento; produção científica; inserção institucional e integração do GRUMAD com outras instituições; conflitos estabelecidos e enfrentados; ações assistenciais construídas coletivamente e o reflexo para clientes e seus familiares.

Após a análise da documentação e para melhor compreender os dados, foi necessário utilizar a estratégia da História Oral, para complementar relatos e fatos registrados por escrito, não suficientemente claros para a interpretação dos resultados ${ }^{9-10}$. Realizamos então, entrevistas semi-estruturadas com integranteschaves que vivenciaram um grande período ou o início do Grupo, visando esclarecer os fatos cujos registros não permitiam uma melhor análise. A análise final do estudo deu-se através da articulação dos dados da documentação e dos obtidos nas entrevistas.

Por envolver seres humanos a pesquisa atendeu as exigências éticas explicitadas na Resolução no 196/ $96^{11}$. Solicitamos o consentimento livre e esclarecido dos entrevistados e a autorização para a divulgação dos resultados. Asseguramos, também o retorno dos resultados obtidos para a instituição e as pessoas envolvidas.

\section{RESULTADOS}

Para melhor compreensão do que constatamos nos documentos e nos relatos orais dividimos, didaticamente, a trajetória do GRUMAD em quatro fases:

Primeira fase: nascimento e estruturação do GRUMAD (1980 -1988)

Oficialmente, o Grupo Multiprofissional de Atendimento ao Diabético do HU-UFSC nasceu em 1987, enquanto grupo organizado. As documentações*, solicitando a sua implantação e divulgação, são de 13 de abril de 1987, destacando-se entre elas** a que solicitou a oficialização do GRUMAD no Hospital Universitário. O ofício esclarecia que o Grupo estaria vinculado ao serviço de Endocrinologia - Unidade de Diabetes, descrevia as atividades propostas e relacionava os membros que o compunham. Em anexo ao ofício, havia uma cópia do documento que detalhava o histórico do Grupo e as atividades que vinham sendo desenvolvidas até aquele momento. Percebemos que, apesar de a solicitação da oficialização acontecer nessa data, o Grupo já funcionava há pelo menos três anos. Os outros ofícios informavam sobre a criação do Grupo às autoridades da UFSC e externas a ela.

A abertura do HU (1980), a relevância do Diabetes Mellitus (DM), o conhecimento sobre a atuação de grupos multidisciplinares no País, foram argumentos utilizados, nos documentos encontrados, para a criação do GRUMAD. A abordagem multiprofissional

*Ofícios de números 1 até 19/GDHU/1987, endereçados a várias autoridades da época, assinados por profissionais de diversas disciplinas; **Ofício de número 001/87, endereçado ao diretor geral do HU/UFSC;

Texto Contexto Enferm 2005 Abr-Jun; 14(2):213-21. 
era assim defendida: ela tem obtido maiores sucessos na compensação clínica do paciente diabético, do que a atuação uniprofissional, por mais eficiente que a mesma possa ser.

A Entrevistada 1 afirmou que o embrião do GRUMAD surgiu mesmo em 1980, ocasião da abertura do Hospital Universitário, caminhando paralelamente com a evolução da disciplina de endocrinologia do curso de medicina. A oficialização do Grupo deuse em 1987, quando ocorreu o $1^{\circ}$ Encontro Nacional de Educação em Diabetes e o Grupo levou o seu primeiro trabalho coletivo intitulado "Manual de Orientação ao Diabético".

Os professores endocrinologistas dessa época, formados no Rio de Janeiro, tinham experiência em uma instituição com práticas de integração profissional entre médicos e enfermeiras. A equipe médica percebia a necessidade de um enfermeiro "volante" que circulasse no hospital e que acompanhasse os clientes diabéticos. Assim, a equipe médica convidou, inicialmente, a enfermeira da Unidade de Internação de Clínica Médica para participar da "corrida de leitos" aos clientes diabéticos internados e, posteriormente, a enfermeira do Serviço Ambulatorial. Nessa atividade a equipe multiprofissional percorria as unidades de internação de clínica médica visitando os clientes diabéticos (Entrevistada 1). Contribuiu, também, para a integração da enfermagem o fato de, neste período, já existir no HU a consulta de enfermagem e o trabalho de educação em saúde desenvolvido pelas enfermeiras no Ambulatório.

As enfermeiras já integravam o Grupo por volta dos anos de 1984/85***. Outro documento**** evidenciava esta integração, pois esclarecia sobre a consulta de enfermagem, aprovada naquele período, e a sua implantação no HU, além das atividades já realizadas de pré e pós-consulta. Destacava, também, que os clientes diabéticos já vinham tendo esse atendimento multiprofissional desde junho de 1985.

Nos registros de 1985 consta a participação de três profissionais de nutrição e nos de 1986 a participação de uma odontóloga, professora do Departamento de Estomatologia da UFSC. Já nessa época o
Grupo acenava para a integração de outros profissionais como num documento ${ }^{* * * * *}$ em que se solicitava um professor da área de Psicologia para atuar no Ambulatório. Dois anos mais tarde houve a integração do profissional de Educação Física ao Grupo.******

Os documentos analisados apontaram a integração gradativa de vários profissionais da área de saúde no GRUMAD, embora se perceba a dificuldade de fixação de profissionais como o de psicologia, cuja atuação tem sido circunstancial até hoje. Além disso, profissionais de diferentes áreas uniram-se gradativamente ao Grupo como voluntários, para o atendimento ou realização de algum estudo específico.

O documento de 1987, sobre o histórico do Grupo, salientava as funções dos profissionais e que caberia a cada disciplina elaborar a sua rotina de trabalho, a ficha de anamnese a ser utilizada no atendimento, assim como o Manual de Orientação ao Paciente. A Entrevistada 1 deixou claro que pela característica do trabalho da enfermagem foi possível organizar os registros e documentações do GRUMAD.

No histórico do GRUMAD constava, ainda, a existência de reuniões semanais, às quintas-feiras pela manhã, nas unidades de internação de clínica médica do HU, com o objetivo de: discutir a organização do Grupo e atividades a serem desenvolvidas; realizar estudos de casos de clientes internados e programar plano terapêutico individual para os clientes, onde cada profissional ficaria responsável pelas orientações específicas de sua área. No entanto, ao rever as atas das reuniões da equipe do Ambulatório, quase não existem informações sobre discussões clínicas e estudos de caso.

Apesar da ausência de registros escritos, o atendimento do Ambulatório ainda tem sido suspenso nas quintas-feiras para que as reuniões continuem a ocorrer na Unidade de Internação. Nestas reuniões têm sido discutidos os casos dos clientes, temas científicos, atualizações e os projetos que devem ser desenvolvidos. No Ambulatório, as discussões de casos são realizadas nas segundas-feiras, simultaneamente ao atendimento, de acordo com a necessidade identificada por qualquer membro da equipe (Entrevistada 1).

\footnotetext{
***Documento dessa época, endereçado à Sub-Diretoria de Enfermagem, solicitava a participação de uma enfermeira no GRUMAD, assim dedu乏imos que foi, nesse periodo, que três enfermeiras (uma das quais professora) passaram a atuar no Grupo.

****Correspondência de 24/06/1986, da chefia da Divisão de Pacientes Externos da Sub-Diretoria de Enfermagem, para os chefes do Serviço de Apoio Médico Assistencial e do Serviço Médico de Ambulatório, solicitando o agendamento da consulta de enfermagem ambulatorial. *****Ofício de 04/08/1986, do Chefe do Serviço de Endocrinologia e Coordenador do Grupo, para a Chefia do Departamento de Psicologia. ******Ofício 001/88, de 25/04/88, para o Diretor do Centro de Esportes da UFSC. Consultava sobre a possibilidade de participação de um professor para o atendimento aos clientes no ambulatório e um professor para ministrar a palestra "Valor do exercício físico no DM".
} 


\section{Segunda fase: organização, crescimento e consolidação do GRUMAD (1989 - 1991)}

A segunda fase concentrou a maior parte dos registros em ata, dando a entender que nela ocorreu o maior número de reuniões do Grupo, com maior número e diversidade de profissionais participantes. Houve a preocupação com as discussões e registros sobre organização do grupo, deixando visível o processo de experiência prática e avaliação constante das atividades desenvolvidas. Identificamos a produção e apresentação de trabalhos em eventos científicos, demonstrando a preocupação constante na construção e divulgação do conhecimento e a necessidade de incorporação de diferentes profissionais ao Grupo.

O espírito de construção de um trabalho em grupo ficou evidenciado nas ações, entre as quais destacaram-se: criação de um registro unificado, com ficha única de histórico, para todos; elaboração e socialização de condutas de cada área; definição de papéis entre os membros do GRUMAD; divisão de atribuições e tarefas na organização do atendimento e nas reuniões; propostas de educação continuada; intenção em firmar um espaço político-institucional e de liderança científica na área; busca constante de recursos e apoio financeiro, material e de pessoal; produção de material educativo e de manuais para utilização no atendimento; conquista de espaço físico para a consolidação e ampliação do Ambulatório.

A participação da enfermagem, nesse período, destacou-se pelo trabalho de elaboração das suas atribuições, indicado como referência para as outras categorias, pela presença marcante nas atividades educativas da Sala de Espera e pela implantação da Consulta de Enfermagem.

\section{Terceira fase: visibilidade interna e externa do GRUMAD (1992 - 1995)}

Os documentos existentes indicaram a diminuição do número e da qualidade dos registros nas atas desse período, prejudicando a compreensão dos temas discutidos, das decisões tomadas e dos profissionais participantes. Os registros apontaram que a discussão do grupo centrou-se, principalmente, na sua organização e funcionamento, sendo que os temas registrados diziam respeito à dinâmica de atendimento. Aparentemente esta discussão visava adequar a organização às necessidades que foram surgindo no desenvolvimento do trabalho. Apareceram as primeiras menções sobre a participação da área de Serviço So- cial, deixando transparecer uma liderança e a conquista de um espaço político deste grupo no GRUMAD.

Entre as atividades promovidas destacaram-se: a organização de atividades extra-ambulatório, com os objetivos de integração e educação em saúde para os clientes; o contato com setores e especialistas para garantir o encaminhamento dos clientes, em caso de problemas e complicações; a indicação de ações educativas para o autocuidado; o acompanhamento pelo mesmo profissional médico evitando rodízio, criando maior vínculo e aprofundamento no caso; a organização do espaço físico, dos materiais e dos grupos operativos para o atendimento; a realização de cursos de treinamento para profissionais externos; a realização de estudos de caso; a divulgação das atividades físicas organizadas pelo Centro de Desportos da UFSC.

Percebeu-se, também, a intenção dos integrantes do Grupo em dinamizar o trabalho com o cliente utilizando-se de materiais audiovisuais e a preocupação com a integração de outras profissões, nutrição e psicologia. Constatamos a intensa movimentação e motivação do Grupo para ocupação deste espaço multiprofissional, dando visibilidade ao trabalho.

\section{Quarta fase: mantendo a rotina de trabalho do Grupo (1996 - 2003)}

Neste período apenas duas reuniões foram registradas, uma em abril de 1996 e outra em março de 1998, quando terminaram as anotações no Livro de Ata. Estas atas eram resumidas, registradas em tópicos, dificultando ao leitor a compreensão dos conteúdos discutidos e das decisões tomadas. Os assuntos referiam-se aos horários, locais e profissionais que estariam atendendo, a divulgação de eventos, o contato com especialistas e a necessidade de selecionar casos para estudo. As dificuldades para a contratação de profissionais, nas áreas de nutrição e de psicologia, ainda continuavam a ser descritas nas atas.

Com relação à diminuição dos registros sobre as atividades do GRUMAD nessa fase, as duas entrevistadas justificaram a situação pelo crescimento na demanda de atendimento e pela abertura da residência médica, acarretando acúmulo de atividades, sobreposição de funções e sobrecarga de trabalho. As explicações indicaram que a ausência de registro foi devida ao excesso de trabalho dos membros e não por falta de atuação do Grupo.

Nos relatos das entrevistadas foram identificados os fatores propulsores e os limitantes ao avanço 
do GRUMAD na realidade institucional. Dentre os aspectos positivos foram destacados: o reconhecimento da Sala de Espera como um espaço importante para toda assistência, com a modificação do horário das consultas para permitir a participação dos diferentes profissionais; a elaboração pela equipe de um Termo de Compromisso Mútuo que foi posteriormente discutido e referendado pela clientela, estabelecendo a co-responsabilidade do cliente/família no tratamento e definindo o espaço de cada um; a elaboração de uma Home Page que tem despertado o interesse da equipe e a participação de residentes; a capacitação de equipes das Unidades Básicas de Saúde, para o atendimento e monitorização do cliente com diabetes; a participação de voluntários e a participação em eventos com apresentação de trabalhos científicos dos membros do Grupo (Entrevistada 2).

O GRUMAD sempre teve como aspecto positivo a discussão de igual para igual dos profissionais do Grupo, todos comungavam da mesma filosofia de trabalho. A entrevistada reforçou que o profissional para atuar nesse tipo de grupo precisa ter um determinado perfil, envolvendo-se com a causa do cliente crônico (Entrevistada 1).

Os aspectos considerados negativos na evolução e dinâmica do Grupo, foram: a mudança dos membros da equipe; a deficiência de pessoal, espaço físico e apoio institucional (Entrevistada 2). Outro aspecto foi que os clientes atendidos nas unidades de internação, em sua maioria, não estão sendo incluídos no atendimento do GRUMAD, devido à restrição de espaço físico e de profissionais (Entrevistada 1).

A identidade do Grupo, enquanto equipe multidisciplinar ou interdisciplinar, ficou prejudicada por causa das variações que ele sofreu ao longo de sua história, ora os profissionais trabalhando de modo separado, ora realizando ações integradas. A entrada de novos profissionais, com outra visão de atendimento, em um determinado período, quase levou o GRUMAD à extinção, tendo sido difícil resgatar a filosofia inicial (Entrevistada 2).

\section{DISCUSSÃO}

\section{GRUMAD: um trabalho com perspectiva interdisciplinar?}

A perspectiva interdisciplinar, em todos os campos do conhecimento, coloca-se na atualidade como uma exigência, uma forma de resistência à prática extremamente fragmentada que foi adotada pela ciência no último século. No campo da saúde, a discussão surge a partir da constatação que a especialização exagerada levou a uma não compreensão global do ser humano e do processo saúde-doença.

O modelo biomédico, fortemente alicerçado no pensamento cartesiano, divide o corpo humano em partes, como em uma máquina. Reduz estas partes a fragmentos cada vez menores, de certa forma detendo-se apenas nos problemas fisiológicos. Deixa de entender que o fisiológico é apenas uma parte do todo. Esta abordagem mostra-se cada vez mais incapaz de compreender a condição humana, seja na situação de saúde ou de doença. Então, a interdisciplinaridade como prática de superação da realidade deve ser praticada ${ }^{12}$.

As experiências desenvolvidas por grupos institucionais de assistência a um tipo específico de clientes surgem da necessidade de integração dos saberes e desenvolvimento prático, em busca da melhoria da qualidade da assistência. Neste sentido, recebem diversas denominações dependendo do foco unificador do grupo. O GRUMAD surge a partir desta idéia e da experiência de alguns de seus profissionais em outras realidades. Colocou-se como grupo multidisciplinar, no entanto, a sua trajetória mostra a tendência clara do seu potencial interdisciplinar na assistência ao cliente com diabetes.

Ao realizar este estudo constatamos que a proposta desenvolvida pelo GRUMAD representa uma mudança na implementação da assistência, demonstra a preocupação com o cliente e com a produção do conhecimento na área. Suas ações têm concentrado formas de integração entre os saberes, articulando a prática e a construção do conhecimento, compreendendo que a sua concretização exige um pensamento central que ligue as diversas disciplinas em torno de um projeto comum. Encontramos no GRUMAD aspectos que evidenciaram que a integração dos seus membros sempre teve um foco comum, descrito pela enfermeira entrevistada como a filosofia do Grupo.

A filosofia do Grupo está baseada na premissa de que a assistência ao cliente diabético deve ter o objetivo de torná-lo co-responsável pelo seu cuidado, através de um processo educativo contínuo que inclua diferentes disciplinas. Essa premissa é reforçada pelo processo de integração dos membros, a partir do somatório de conhecimentos de áreas distintas, onde há o respeito mútuo pela particularidade de cada profissão e o reconhecimento que deve haver complementaridade para uma ação mais efetiva (Entrevistadas 1 e 2).

O GRUMAD constitui-se em um grupo que 
compartilha uma filosofia sobre a assistência às pessoas diabéticas, reconhece a importância dos diferentes saberes na prática assistencial e compreende a pessoa diabética como alguém que vivencia uma condição de saúde, sendo possivel aos profissionais ajudá-lo a enfrentar a situação. Organiza suas ações de forma a propiciar a participação dos diversos profissionais e da pessoa diabética (Entrevistada 2).

Abordando a interdisciplinaridade a partir do trabalho realizado pelo GRUMAD percebemos que o Grupo possui vínculos profissionais sólidos, particularmente nas relações interpessoais médico/enfermeiro, sustentáculos do trabalho, que vêm possibilitando uma prática participativa, crítica e reflexiva. $\mathrm{O}$ vínculo entre esses profissionais é complementar e interdependente, centrando o foco do atendimento no cliente diabético, norteado pela definição de papéis e funções descritas no Manual de Rotinas do Ambulatório, elaborado no início do Grupo. Porém, ressalta-se a importância da participação de profissionais voluntários que auxiliam no atendimento, influenciam e dão destaque ao Grupo com suas ações (Entrevistada 2).

As suposições sobre a interdisciplinaridade precisam, neste caso, serem formuladas a partir da práxis, momento em que elas se concretizam e se tornam singulares no espaço estudado. Neste sentido, é no diálogo voltado à práxis concreta, que se possibilita a sua própria qualificação e aprimoramento ${ }^{6}$. O desafio histórico é compreender a interdisciplinaridade a partir de sua realização, levando em consideração os limites e as possibilidades vislumbradas, buscando o que é melhor para superar a realidade.

Outro aspecto identificado no GRUMAD foi a consciência que o projeto coletivo não exclui o desenvolvimento próprio de cada disciplina, a manutenção de suas especificidades, bem como as contribuições de cada grupo profissional para a manutenção do grupo. A interdisciplinaridade, neste sentido, firma-se a partir do conhecimento disciplinar consistente e em permanente desenvolvimento.

Em relação à enfermagem, fica claro que ela vem ocupando um espaço fundamental na dinâmica do Grupo. Esta posição foi referendada no depoimento que, em determinados momentos, o Grupo se manteve por investimento da enfermeira (Entrevistada 1). O papel da Enfermagem em atividades de interação grupal tem sido reconhecido historicamente. Ela vem coordenando o cuidado ao cliente hospitalizado, utilizando no seu modo de cuidar a interação como um dos elementos que alicerça a sua prática cotidiana.

$\mathrm{Na}$ interdisciplinaridade "um fato importante a considerar é que tudo que envolve a vida não pode mais ser tratado de forma fragmentada, sob o risco de não ser compreendido ou de não alcançar resolutividade. Porque a vida é complexa, o cuidar da vida também exige complexidade de ações, o que nos levará, necessariamente, a buscar parceiros [...]" 13:154.

Esta reflexão destaca que a visão interdisciplinar pressupõe outras habilidades para garantir o cuidado integral ao cliente internado e também nas unidades ambulatoriais, devendo este ser construído coletivamente entre as várias áreas. Percebemos que o trabalho desenvolvido pelas enfermeiras no GRUMAD aponta para este caminho, na medida que investem na formação de grupos, nas Salas de Espera e nas atividades educativas buscando um modelo no cuidado do cliente diabético e procurando, também, o envolvimento de outros membros da equipe.

Aspectos limitantes para o trabalho grupal, como a constante discussão acerca dos recursos humanos, materiais, de área física e sobrecarga de trabalho, foram apontados para enfatizar a necessidade de apoio institucional para o desenvolvimento de um trabalho de qualidade e o aproveitamento do potencial do Grupo. Sem essas condições a atividade grupal limitase ao atendimento no espaço institucional, deixando de realizar ações que poderiam contribuir com a instituição, o ensino, a pesquisa e a sociedade.

A exemplificação deste fato foi exposta na afirmação de que a manutenção do Grupo tem exigido investimento pessoal de alguns dos seus integrantes e que não existe contrapartida institucional, pois a estrutura não reconhece o papel dessa equipe e as contribuições que ela pode dar. Apesar deste ser o primeiro grupo multiprofissional da instituição, perden espaso para outros criados mais tarde (Entrevistada 2).

A análise da situação, no entanto, não pode ser realizada descolada de uma análise geral da sociedade. O aumento de atendimento do GRUMAD e a crise financeira que o hospital universitário têm enfrentado refletiram no agravamento da carência de infra-estrutura física, humana e material. A restrição do espaço físico para as atividades educativas; a impossibilidade de realização de alguns exames importantes; a falta de equipamentos básicos, a não implantação da área para hospital-dia e a carência de recursos humanos, vêm dificultando a ampliação e melhoria da assistência, do ensino e o desenvolvimento de pesquisas na área (Entrevistadas 1 e 2 ).

Apesar das dificuldades apontadas para o desenvolvimento do trabalho, as entrevistadas ressaltaram a necessidade da identificação do profissional com 
o trabalho que realiza para que este tenha resultados positivos. Esta identificação ganha um destaque significativo na manutenção do Grupo por tantos anos, numa eterna busca do novo e no reconhecimento do conhecimento inacabado, sempre sujeito a mudanças. Neste aspecto o ponto de partida da abordagem interdisciplinar seria a articulação do conhecimento do fator humano e da prática, isto porque não existe interdisciplinaridade como decorrência do puro desejo de saber, independente de um projeto e de uma motivação extraordinária ${ }^{14}$.

Ao analisarmos a trajetória do GRUMAD percebemos que o registro irregular sobre o trabalho desenvolvido foi um aspecto negativo. As próprias entrevistadas reconheceram esta deficiência concordando que na história documental ficou um vazio. Sem a memória dos integrantes do Grupo pareceria que, em determinados períodos, o GRUMAD teria reduzido sua atuação, deixando de realizar atividades e perdendo a sua identidade.

Como todo projeto inovador, as iniciativas interdisciplinares necessitam de registros, seja para a sua própria compreensão e avanço, seja para a divulgação e contribuição com outras experiências similares. A interdisciplinaridade, enquanto processo em contínua construção, necessita ser documentada para ganhar visibilidade como alternativa ao modelo hegemônico de atenção à saúde e produção do conhecimento.

Dentre os princípios apontados ${ }^{15}$ para que ocorra a interdisciplinaridade, o GRUMAD conseguiu atingir, em sua trajetória, os seguintes:

1) é organizado de modo a desenvolver um trabalho conjunto, pois seus membros determinam quem vai desenvolver o trabalho e com que atores, possibilitando o debate de diferentes formações e especializações;

2) o seu objeto de estudo e métodos são gradativamente estabelecido pela equipe, os integrantes do Grupo se orientam, por objetivos discutidos de forma cooperativa;

3) a solução de problemas interdisciplinares acontece por meio da aprendizagem social, do estranhamento e da comunicação dos achados científicos. O Grupo desempenhou em parte este princípio, quando influenciou nas soluções dos problemas sociais dos clientes, interna e externamente ao HU, buscando integração com outras instituições, interferindo no sistema de referência e contra-referência. Promoveu e participou de debates públicos com a sociedade, academia e clientes, buscando recursos para de- fender os interesses de saúde dos clientes. Ampliou e divulgou o conhecimento quando treinou profissionais da rede básica e estabeleceu protocolos para serem implantados no HU e nas Redes Municipal e Estadual de Saúde;

4) o princípio da abertura e formação de redes, foi identificado quando o GRUMAD se submeteu à crítica de outros grupos, através da divulgação de seus trabalhos em eventos e congressos científicos e, também, a crítica e avaliação da sociedade, trabalhando com entidades não governamentais e associações de diabéticos, inclusive estimulando-as e assessorando-as;

5) o princípio da autonomia dos membros do Grupo, pois os saberes distintos foram desenvolvidos e visualizados como capacidade de criação e respeitados pelos membros;

6) postura de cooperação. Foi afirmado nas entrevistas que para compor o GRUMAD o profissional deveria estar comprometido com a causa, vestindo a camisa (Entrevistada 2). Que para atuar, junto a essa clientela de clientes crônicos, o profissional necessita ter um perfil psicológico diferenciado, não pode ser imediatista, já que se trata de uma patologia que necessita de controle contínuo e por tempo indeterminado (Entrevistada 1). Nessas expressões ficou forte a noção de que existe a defesa de um ideal, que tem conseguido unir o grupo durante tantos anos;

7) o exercício de trabalhar as diferenças. Os registros documentais e as entrevistas revelaram a existência de conflitos e divergências entre os membros do Grupo, confirmando uma das características da prática interdisciplinar. Cada profissional respeita o seu espaco e limite, assim como o do outro. [...] nas vezes que ocorreram dificuldades, a opinião e a experiência dos membros mais antigos foram ouvidas, existindo um espaço para o diálogo e as mudanças necessárias (Entrevistada 1).

Para implementar a interdisciplinaridade é necessário seguir princípios “[...] é preciso conservar as noções chave que estão implicadas nisso, ou seja, cooperação; melhor, objeto comum; e, melhor ainda, projeto comum" "5:115.

Inicialmente, o foco catalisador para a formação do embrião do GRUMAD foi a visita e a discussão de casos clínicos de clientes diabéticos internados. $\mathrm{Na}$ medida em que o Grupo foi-se organizando e fortalecendo, as atividades ambulatoriais de cunho mais educativo ganharam força, e passaram a ser a principal atividade da equipe. Nesse momento o projeto comum do Grupo passou a ser a atuação sobre o autocuidado, de forma a prevenir as complicações e 
reduzir as internações. No cotidiano observou-se que as pessoas com diabetes atendidas pelo Grupo raramente necessitam de internação [...] costumam procurar o Grupo quando apresentam alguma alteração, possibilitando, assim, a atuação imediata da equipe [...] alguns destes clientes não internam bá mais de 20 anos (Entrevistada 1).

\section{CONSIDERAÇÕES FINAIS}

Este estudo, através da história documental e oral, propiciou o resgate da trajetória do GRUMAD para compreender o trabalho em saúde na nossa realidade, com perspectiva multi e/ou interdisciplinar. Apesar de o GRUMAD se auto-intitular multiprofissional, identificamos que se tratava de um grupo com potencial para a interdisciplinaridade, por isso deve ser estimulado a superar suas fragilidades, buscando o fortalecimento da equipe e de suas ações, assim como a valorização de seus resultados.

Os limites encontrados no desenvolvimento desta prática, embora consistam em entraves para o seu crescimento não invalidam as conquistas já realizadas e a sua importância no contexto do trabalho assistencial em saúde desenvolvido no HU-UFSC.

Os dados indicam que o trabalho do GRUMAD possui características de um atendimento cooperativo, participativo, com diálogo aberto e igualitário, confirmando uma das características da prática interdisciplinar. As ações desenvolvidas e o envolvimento dos profissionais na construção de uma assistência de melhor qualidade demonstraram o potencial desta experiência na mudança da prática hegemônica em saúde em nossa sociedade.

\section{REFERÊNCIAS}

1 Matos E. Novas formas de organização do trabalho e aplicação na enfermagem: possibilidades e limites [dissertação]. Florianópolis (SC): Programa de PósGraduação em Enfermagem/ UFSC; 2002.

2 Pires D. Reestruturação produtiva e trabalho em saúde no Brasil. São Paulo: Annablume; 1998.
3 Capella B. Uma abordagem sócio-humanista para um "modo de fazer" o trabalho de enfermagem. Pelotas: UFPELK; 1998. (Série Teses - Enfermagem UFSC).

4 Peduzzi M. Equipe multiprofissional de saúde: conceito e tipologia. Rev Saúde Pública. 2001; 35(1):103-9.

5 Morin E. A cabeça bem-feita. Rio de Janeiro: Bertrand Brasil; 2000.

6 Almeida Filho N. Transdisciplinaridade e saúde coletiva. Ciênc Saúde Colet. 1997; 2(1-2): 5-20.

7 Japiassú H. Interdisciplinaridade e patologia do saber. Rio de Janeiro: Imago; 1976.

8 Ferreira ABH. Novo dicionário Aurélio da língua portuguesa. 2a ed. Rio de Janeiro: Nova Fronteira; 1989.

9 Vasconcelos EM. Complexidade e pesquisa interdisciplinar: epistemologia e metodologia operativa. Petrópolis: Vozes; 2002.

10Borenstein MS, Althoff CR. Pesquisando o passado. Rev Bras Enferm. 1995 Abr-Jun; 48(2): 144-9.

11Conselho Nacional de Saúde (BR). Aprova as diretrizes e normas regulamentadoras de pesquisas envolvendo seres humanos. Resolução n. 196, de 10 de outubro de 1996. Brasília: O Conselho; 1996.

12Capra F. O ponto de mutação: a ciência, a sociedade e a cultura emergentes. São Paulo: 1995.

13 Leopardi MT, Santos I, Sena RR. Tendências de enfermagem no Brasil: tecnologias do cuidado e valor da vida. In: Anais do $51^{\circ}$ Congresso Brasileiro de Enfermagem; 1999 Out 27; Florianópolis, Brasil. Florianópolis: ABEn-Seção SC; 2000.

14 Nunes ED. A questão da interdisciplinaridade no estudo da saúde coletiva e o papel das ciências. In: Canesqui AM. Dilemas e desafios das ciências sociais na saúde coletiva. São Paulo/ Rio de Janeiro: HUCITEC-ABRASCO; 1995. p.95113.

15Wallner F. Sete princípios da interdisciplinaridade no realismo construtivista. In: Jansrtsch AP, Bianchetti L, organizadores. Interdisciplinaridade: para além da filosofia do sujeito. Petrópolis, RJ: Vozes; 1995. p.85 - 96. 